University of Wollongong

Research Online

Faculty of Engineering and Information

Faculty of Engineering and Information

Sciences - Papers: Part A

Sciences

$1-1-2012$

Induction motors subject to regular voltage fluctuations: Stator and rotor current analysis from a heating perspective

Kun Zhao

University of Wollongong, kz664@uowmail.edu.au

Philip Ciufo

University of Wollongong, ciufo@uow.edu.au

Sarath Perera

University of Wollongong, sarath@uow.edu.au

Follow this and additional works at: https://ro.uow.edu.au/eispapers

Part of the Engineering Commons, and the Science and Technology Studies Commons

Research Online is the open access institutional repository for the University of Wollongong. For further information contact the UOW Library: research-pubs@uow.edu.au 


\title{
Induction motors subject to regular voltage fluctuations: Stator and rotor current analysis from a heating perspective
}

\author{
Abstract \\ Induction motors are widely applied in industry. Their performance strongly depends on relative power \\ supply quality, such as voltage sags, harmonics, voltage unbalance and voltage fluctuations. This paper \\ investigates the impact of voltage fluctuations on induction motor performance, particularly the stator \\ and rotor current variation characteristics. An induction motor steady state analysis method is proposed \\ when the motor is subjected to regular voltage fluctuations. The dynamic model of an induction motor is \\ used in order to represent the induction motor instantaneous response. Furthermore, the correlative \\ simulation and experiment work are presented in order to illustrate the impact of voltage fluctuations. The \\ stator and rotor RMS current magnitudes of the motor increase dramatically and this effect keeps \\ deteriorating with modulation frequency and voltage change increases. The increase in RMS current will \\ increase losses, resulting in motor winding temperature rise, subsequently accelerating the ageing \\ process.

\section{Keywords} \\ regular, subject, motors, induction, perspective, fluctuations, heating, voltage, analysis, current, rotor, \\ stator

\section{Disciplines} \\ Engineering | Science and Technology Studies

\section{Publication Details} \\ K. Zhao, P. Ciufo \& S. Perera, "Induction motors subject to regular voltage fluctuations: Stator and rotor \\ current analysis from a heating perspective," in ICHQP 2012: 15th IEEE International Conference on \\ Harmonics and Quality of Power, 2012, pp. 642-648.
}




\title{
Induction Motors Subject to Regular Voltage Fluctuations: Stator and Rotor Current Analysis from a Heating Perspective
}

\author{
Kun Zhao, Phil Ciufo, Senior Member, IEEE, and Sarath Perera, Member, IEEE
}

\begin{abstract}
Induction motors are widely applied in industry. Their performance strongly depends on relative power supply quality, such as voltage sags, harmonics, voltage unbalance and voltage fluctuations. This paper investigates the impact of voltage fluctuations on induction motor performance, particularly the stator and rotor current variation characteristics. An induction motor steady state analysis method is proposed when the motor is subjected to regular voltage fluctuations. The dynamic model of an induction motor is used in order to represent the induction motor instantaneous response. Furthermore, the correlative simulation and experiment work are presented in order to illustrate the impact of voltage fluctuations. The stator and rotor RMS current magnitudes of the motor increase dramatically and this effect keeps deteriorating with modulation frequency and voltage change increases. The increase in RMS current will increase losses, resulting in motor winding temperature rise, subsequently accelerating the ageing process.
\end{abstract}

Index Terms-Voltage fluctuation, flicker, induction motor, stator current, rotor current.

\section{NOMENCLATURE}

$\begin{array}{ll}V_{p} & \text { Amplitude of the fundamental AC voltage } \\ \Delta V & \text { Voltage magnitude variation } \\ f_{c} & \text { AC voltage fundamental frequency } \\ f_{m} & \text { Modulation frequency } \\ m & \text { Modulation depth } \\ T_{e} & \text { Induction motor torque } \\ T_{L} & \text { Load torque } \\ J & \text { Rotor inertia } \\ P & \text { Induction motor poles } \\ \omega_{e} & \text { Synchronous speed } \\ \omega_{r} & \text { Rotor electrical angular speed } \\ \omega_{m} & \text { Rotor mechanical angular speed } \\ L_{s} & \text { Stator inductance } \\ L_{r} & \text { Rotor inductance } \\ L_{m} & \text { Mutual inductance } \\ S & \text { Laplace operator } \\ s_{b} & \text { Slip at fundamental angular frequency } \\ s_{\text {usb }} & \text { Slip at USB angular frequency } \\ s_{\text {lsb }} & \text { Slip at LSB angular frequency }\end{array}$

Kun Zhao, Phil Ciufo, and Sarath Perera are with the School of Electrical, Computer and Telecommunications Engineering, at the University of Wollongong and are Members of the Endeavour Energy Power Quality and Reliability Centre, NSW 2522, Australia (E-mails: kz664@uowmail.edu.au, ppc@uow.edu.au and sarath@uow.edu.au).

NOTICE: this is the authors' version of a work that was accepted for publication. Changes resulting from the publishing process, such as peer review, editing, corrections, structural formatting, and other quality control mechanisms may not be reflected in this document. Changes may have been made to this work since it was submitted for publication. A definitive version was subsequently published in the Proceedings of the 15th IEEE International Conference on Harmonics and Quality of Power, June 2012 DOI:10.1109/ICHQP.2012.6381214

$\begin{array}{ll}f_{s} & \text { Slip frequency (in Hz) } \\ \mathbf{V} & \begin{array}{l}\text { Induction motor per-phase equivalent voltage vec- } \\ \text { tor }\end{array} \\ \mathbf{I} & \begin{array}{l}\text { Induction motor per-phase equivalent current vec- } \\ \text { tor }\end{array} \\ \text { subscript } & \text { Stator } q \text { axes } \\ q s & \text { Stator } d \text { axes } \\ d s & \text { Rotor } q \text { axes } \\ q r & \text { Rotor } d \text { axes } \\ d r & \text { Stator variables } \\ s & \text { Rotor variables } \\ r & \text { Upper-sideband variables } \\ \text { usb } & \text { Lower-sideband variables } \\ l s b & \text { per-phase equivalent fundamental frequency com- } \\ \text { ph } & \text { ponent } \\ & \text { Thévenin impedance }\end{array}$

\section{INTRODUCTION}

$\mathbf{I}$

$\mathrm{N}$ power systems, certain loads are intermittent or show strong fluctuations in power demand. Such load or current variations may lead to voltage fluctuations which in turn can give rise to light intensity fluctuations in lamps, especially incandescent lamps. Furthermore, lamp flicker which arises from voltage fluctuations can be used to indicate electromagnetic compatibility and adherence to planning levels in power systems. The incandescent lamps is slowly being replaced by other, higher efficiency lamp types which are less sensitive to voltage fluctuations [1]. The relaxation of normative flicker limits may be proposed [2] as a consequence of this reduction in sensitivity.

However, the potential detrimental effects caused by voltage fluctuations on electrical equipment should be considered before the flicker limits are relaxed. The induction motor response to regular voltage fluctuations are investigated in [2]-[5]. [2] briefly presents several simulation results related to the effect of the voltage fluctuation phenomenon on electrical equipment performance, including motors, PWM-VSI converters, linear and switched sources. The results show that equipment characteristics such as motor torque and speed, converter voltages and switched source output voltages show little variation when the flicker index $P_{s t}$ is unity. Thus, the authors suggest the flicker limits need to be relaxed and more detailed work should be performed, such as laboratory tests, more tests under $P_{s t}$ values greater than one, and even life expectancy analysis. [3] simulates the three-phase squirrel cage induction motor instantaneous performance in detail with applying sinusoidal voltage fluctuations and comparing the speed, torque 
and motor efficiency response under different voltage change and modulation frequencies. The results obtained show motor speed is more affected by low frequencies and high amplitudes of voltage fluctuations, whilst the torque and efficiency are more affected for middle and high frequencies and amplitudes. However, some applied voltage amplitudes change (up to 20\%) are considered much higher from flicker index perspective. Experimental work using a $7.5 \mathrm{~kW}$ induction motor under rectangular amplitude modulation voltage conditions are carried out and reported in [4], The results show that a few percent amplitude modulation can be critical in terms of motor torque and speed. However, this paper is concerned with motor torque and speed instantaneous variation and the other accumulated impacts, such as stator current profile, induction thermal variation, are not investigated. [5] presents the induction motor stator current and rotor speed behaviour under different voltage fluctuation conditions. Based on a fluxlinkage small-signal model, the relationship between stator current and line voltage can be established. In order to further flicker transfer studies, the results obtained shows that different size induction motors have different responses when subject to various modulation frequencies, especially the upper-side band and lower-side band range. The results also indicate that the induction motor load can help flicker attenuation in power transmission and distribution systems.

Generally, equipment failure caused by power quality issues can be summarised into two categories; instantaneous and accumulated. According to the literature, the instantaneous response caused by voltage fluctuations is of most concern. Amongst the range of various power quality (PQ) issues, flicker is not normally considered as a serious problem since it cannot cause machine breakdown immediately. Nevertheless, the long-term accumulated effect caused by voltage fluctuations should be considered, for example, the machine winding extra power loss and relative temperature increase, etc. Paper [6] investigates the induction motor accumulated effect subject to harmonics and voltage unbalance conditions and proposes one new PQ index which is determined from the analysis of temperature rise in induction motor windings that are tested for long periods of time. Similarly, under voltage fluctuations condition, the impact on the induction motor should be considered, thus, the induction motor stator and rotor current variation and corresponding change in losses is of primary interest in this paper.

This paper is organised as follows: background details in relation to voltage fluctuation and flicker as a power quality issue are reviewed in Section II. The induction motor stator and rotor RMS current analysis when subjected to voltage fluctuations is presented in Section III, including dynamic model and per-phase equivalent circuit analyses. Section IV presents the stator and rotor current profile through a specific simulation and experimental study. Finally, conclusions are presented in Section V.

\section{ReView of Voltage Fluctuations And Flicker}

In a deregulated electricity industry, new concerns have emerged regarding the quality of the power supply as companies tend to focus on their own objectives and interests. One main concern regarding power supply quality is voltage fluctuation. The term flicker, which is derived from the impact that voltage fluctuations have on incandescent lamps such that they are perceived by the human eye to light flicker, has its severity defined by indices described in AS/NZS 61000.3.7 [7]. These indices are used in planning of installations in power system in order to satisfy EMC low-frequency immunity requirement. According to AS/NZS 61000.3.7 [7], voltage fluctuations are variations in the RMS value or the peak value with an amplitude of less than $10 \%$ of the nominal voltage. As Fig. 1 illustrates, $\Delta V$ represents the voltage magnitude variation. Flicker is characterised by the frequency component which ranges from 0.5 to approximately $32 \mathrm{~Hz}$ since flicker sensitivity is higher for the human eye-brain system at these frequencies. Recently, with Distribution Generation (DG) increasing in popularity, PQ issues meet a new challenge for voltage fluctuation, including online monitoring system, flicker trace analysis and flicker mitigation technology, etc [8] [9].

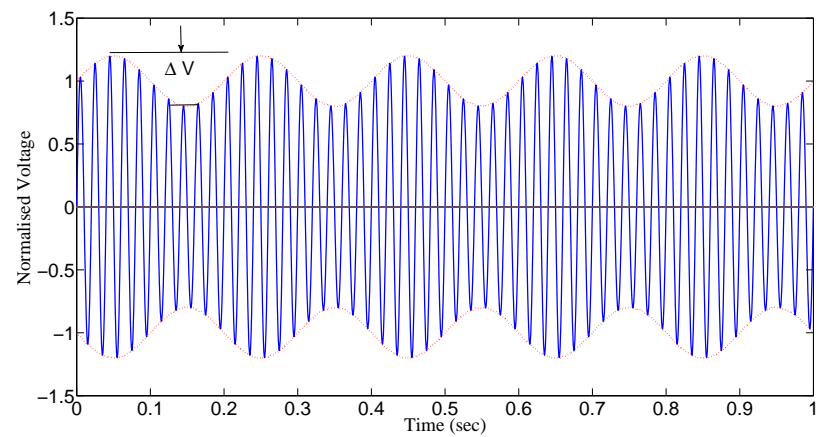

Fig. 1. Typical voltage fluctuations profile

Voltage fluctuations can be classified into different categories: periodic voltage oscillations with constant amplitude, irregular amplitude and continuous random fluctuations. The periodic voltage fluctuation (within a sinusoidal envelope and with constant amplitude but various modulating frequencies) is used to study the induction motor behaviour in this paper. The typical voltage fluctuation profile is illustrated in Fig. 1 and the corresponding instantaneous voltage with the fluctuation components can be expressed as:

$$
\begin{aligned}
v(t) & =V_{p} \sin \left(2 \pi f_{c} t\right)\left[1+m \sin \left(2 \pi f_{m} t\right)\right] \\
m & =\frac{\Delta V}{2 V_{p}}
\end{aligned}
$$

Alternatively, (1) can be expressed as:

$$
\begin{aligned}
v(t)=V_{p} \sin \left(2 \pi f_{c} t\right) & +\frac{m V_{p}}{2} \sin \left(2 \pi\left(f_{c}+f_{m}\right) t-\frac{\pi}{2}\right) \\
& +\frac{m V_{p}}{2} \sin \left(2 \pi\left(f_{c}-f_{m}\right) t+\frac{\pi}{2}\right)
\end{aligned}
$$

where, $V_{p}$ is the amplitude of the fundamental AC voltage. $f_{c}$ is the fundamental frequency and modulation frequency is expressed as $f_{m}$. Moreover, $\Delta V$ represents the voltage magnitude variation and the modulation depth is represented by $m$. According to (2), the flicker voltage source contains two frequency components. One is a super-synchronous frequency, called the upper-sideband (USB), and another is a sub-synchronous frequency, called lower-sideband (LSB).

The severity of voltage fluctuations can be measured using a flickermeter, as defined and stated in AS/NZS 61000.4.15 [10]. Additionally, the level of flicker expressed by the short-term 
flicker severity index, $P_{s t}$ and the long-term flicker severity, $P_{l t}$ can be used in determining compatibility and planning levels.

\section{INDUCTION MOTOR DYNAMIC MODEL}

Typically, induction motors are designed to tolerate a small level of voltage fluctuation. However, certain fluctuation levels can cause serious problems with the motor operation. The dynamic $d-q$ model of an electric machine is one common method used to analyse induction machine performance. $\mathrm{Pa}$ rameters such as torque, stator and rotor current, rotor speed, etc. are readily observed with such a model. The equations that describe the dynamic model are non-linear but can be easily solved using a computer. For a symmetrical, three-phase induction motor, the voltage equation in the synchronously rotating reference frame can be expressed by (3). In (3), $S$ is the Laplace operator and $L_{l s}=L_{s}+L_{m}, L_{l r}=L_{r}+L_{m}$. For the squirrel cage induction motor, $V_{q r}=V_{d r}=0$. The rotor speed $\omega_{r}$ is dependent on the load torque and rotor inertia of the machine which cannot be considered as a constant unless coupled with and infinite inertia load. Thus, electrical torque can be expressed as:

$$
T_{e}=T_{L}+J \frac{d \omega_{m}}{d t}=T_{L}+J \frac{2}{P} \frac{d \omega_{m}}{d t}
$$

where, $T_{L}, J$ are load torque and rotor inertia respectively. Mechanical speed, stator poles are expressed as $\omega_{m}$ and $P$. Alternatively, the torque $T_{e}$ also can be represented by:

$$
T_{e}=\frac{3}{2} \frac{P}{2} L_{m}\left(i_{q s} i_{d r}-i_{d s} i_{q r}\right)
$$

Combined with electrical and mechanical performance, the induction motor dynamic model can be illustrated by using Fig. 2. Such a model can be established using MATLAB/Simulink®.

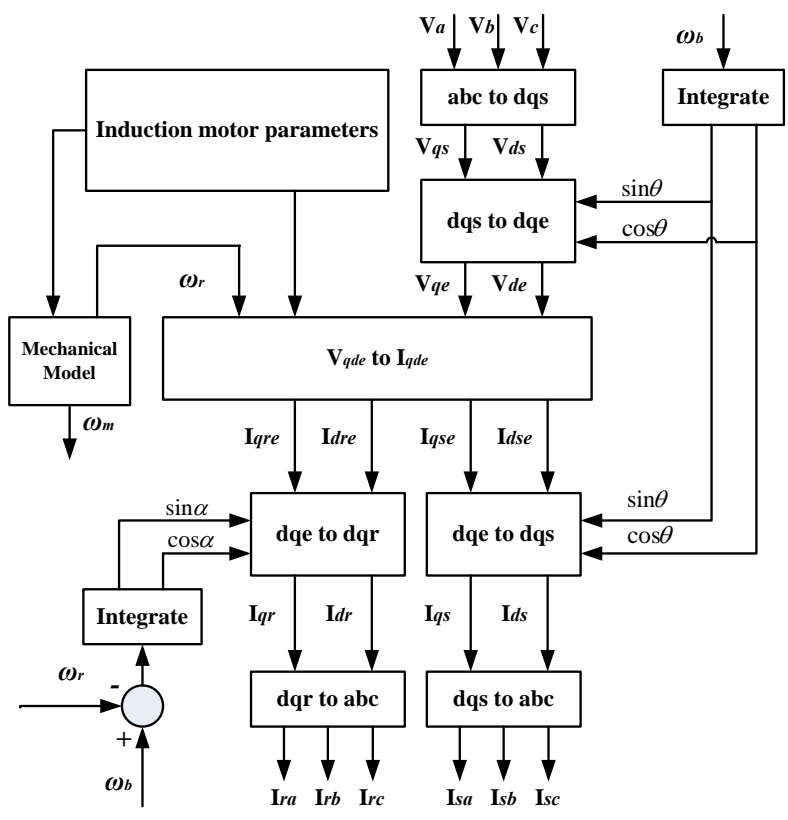

Fig. 2. Induction motor dynamic $d-q$ model

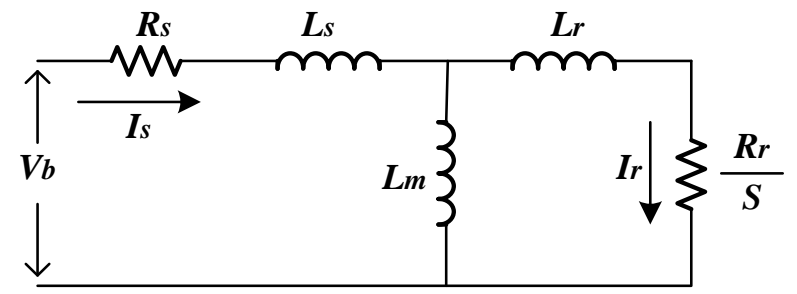

Fig. 3. The per-phase equivalent of an induction motor

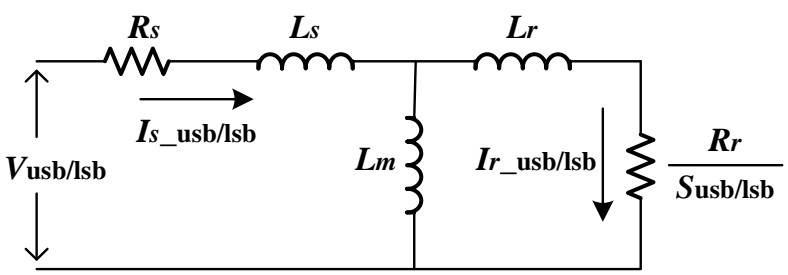

Fig. 4. The side-band component per-phase equivalent of an induction motor

\section{Steady State ANALysis With REGUlaR VOLTAGE FLUCTUATIONS}

An induction machine steady state behaviour analysis can be carried out by using the per-phase equivalent circuit. The typical per-phase equivalent circuit, referred to the stator side, is illustrated in Fig. 3 (the core loss component has been neglected), which has all the speed variation effects concentrated in the impedance term. According to (2), the lineto-neutral voltage of a power supply with a regular sinusoidal fluctuation component can be defined as:

$$
\mathbf{V}=\mathbf{V}_{\mathrm{ph}}+\mathbf{V}_{\mathrm{usb}}+\mathbf{V}_{\mathrm{lsb}}
$$

where;

$$
\begin{aligned}
\mathbf{V}_{\mathrm{ph}} & =V_{p} \sin \left(2 \pi f_{c} t\right) \\
\mathbf{V}_{\mathrm{usb}} & =\frac{m V_{p}}{2} \sin \left(2 \pi\left(f_{c}+f_{m}\right) t-\frac{\pi}{2}\right) \\
\mathbf{V}_{\mathrm{lsb}} & =\frac{m V_{p}}{2} \sin \left(2 \pi\left(f_{c}-f_{m}\right) t+\frac{\pi}{2}\right)
\end{aligned}
$$

It is obvious that the single phase voltage has corresponding upper-sideband and lower-sideband components. Since the sideband voltage magnitude is much less than the fundamental part, the induction motor can be approximately represented by a constant-parameter and linear-equivalent circuit. Therefore, the resultant current can be calculated by applying the superposition principle. According to Fig. 3, the per-phase equivalent circuit can be converted to a side-band equivalent circuit as shown in Fig. 4. Since the rotor speed is related to the fundamental frequency only, the rotor appears practically stationary with respect to USB and LSB components. Mathematically, the slip at the USB and LSB field can be defined as:

$$
s_{\mathrm{usb}}=\frac{\omega_{\mathrm{usb}}-\omega_{r}}{\omega_{\mathrm{usb}}}
$$

$$
s_{\mathrm{lsb}}=\frac{\omega_{\mathrm{lsb}}-\omega_{r}}{\omega_{\mathrm{lsb}}}
$$




$$
\left[\begin{array}{c}
V_{q s} \\
V_{d s} \\
V_{q r} \\
V_{d r}
\end{array}\right]=\left[\begin{array}{cccc}
R_{s}+S L_{l s} & \omega_{e} L_{l s} & S L_{m} & \omega_{e} L_{m} \\
-\omega_{e} L_{l s} & R_{s}+S L_{l s} & -\omega_{e} L_{m} & S L_{m} \\
S L_{m} & \left(\omega_{e}-\omega_{r}\right) L_{m} & R_{r}+S L_{l r} & \left(\omega_{e}-\omega_{r}\right) L_{l r} \\
\left(\omega_{r}-\omega_{e}\right) L_{m} & S L_{m} & \left(\omega_{r}-\omega_{e}\right) L_{l r} & R_{r}+S L_{l r}
\end{array}\right]\left[\begin{array}{c}
i_{q s} \\
i_{d s} \\
i_{q r} \\
i_{d r}
\end{array}\right]
$$

where, $\omega_{\text {usb }}=2 \pi\left(f_{c}+f_{m}\right)$ and $\omega_{\mathrm{lsb}}=2 \pi\left(f_{c}-f_{m}\right)$. Therefore, the stator current $\mathbf{I}_{s}$ and rotor current $\mathbf{I}_{r}$ can be expressed as:

$$
\begin{aligned}
& \mathbf{I}_{s}=\mathbf{I}_{\mathrm{ph}_{\_} s}+\mathbf{I}_{\mathrm{usb}_{\_} s}+\mathbf{I}_{\mathrm{lsb} \_} s \\
& \mathbf{I}_{r}=\mathbf{I}_{\mathrm{ph}_{-} r}+\mathbf{I}_{\mathrm{usb}_{-} r}+\mathbf{I}_{\mathrm{lsb} \_} r
\end{aligned}
$$

Alternatively,

$$
\begin{aligned}
\mathbf{I}_{\mathrm{ph} \_s} & =\frac{\mathbf{V}_{\mathrm{ph}}}{Z_{\mathrm{th} \_\mathrm{b}}} \\
\mathbf{I}_{\mathrm{usb}_{-} s} & =\frac{\mathbf{V}_{\text {usb }}}{Z_{\mathrm{th} \text { usb }}} \\
\mathbf{I}_{\text {lsb_s }} & =\frac{\mathbf{V}_{\text {lsb }}}{Z_{\mathrm{th} \text { lsb }}}
\end{aligned}
$$

Where the Thévenin impedance corresponding to each component can be described as:

$$
\begin{aligned}
Z_{\mathrm{th} \_\mathrm{b}} & =\left(R_{s}+j \omega_{b} L_{s}\right)+\frac{j \omega_{b} L_{m}\left(\frac{R_{r}}{S_{b}}+j \omega_{b} L_{r}\right)}{j \omega_{b} L_{m}+\frac{R_{r}}{S_{\mathrm{b}}}+j \omega_{b} L_{r}} \\
Z_{\mathrm{th} \_\mathrm{usb}} & =\left(R_{s}+j \omega_{\mathrm{usb}} L_{s}\right)+\frac{j \omega_{\mathrm{usb}} L_{m}\left(\frac{R_{r}}{S_{\mathrm{usb}}}+j \omega_{\mathrm{usb}} L_{r}\right)}{j \omega_{\mathrm{usb}} L_{m}+\frac{R_{r}}{S_{\mathrm{usb}}}+j \omega_{\mathrm{usb}} L_{r}} \\
Z_{\mathrm{th} \_\mathrm{lsb}} & =\left(R_{s}+j \omega_{\mathrm{lsb}} L_{s}\right)+\frac{j \omega_{\mathrm{lsb}} L_{m}\left(\frac{R_{r}}{S_{\mathrm{lsb}}}+j \omega_{\mathrm{lsb}} L_{r}\right)}{j \omega_{\mathrm{lsb}} L_{m}+\frac{R_{r}}{S_{\mathrm{lsb}}}+j \omega_{\mathrm{lsb}} L_{r}}
\end{aligned}
$$

Additionally,

$$
\begin{aligned}
\mathbf{I}_{\mathrm{ph}_{-} r} & =\mathbf{I}_{s b} \frac{j \omega_{b} L_{m}}{j \omega_{b} L_{m}+\frac{R_{r}}{S_{b}}+j \omega_{b} L_{r}} \\
\mathbf{I}_{\mathrm{usb} \_} r & =\mathbf{I}_{s_{-} \mathrm{usb}} \frac{j \omega_{\mathrm{usb}} L_{m}}{j \omega_{\mathrm{usb}} L_{m}+\frac{R_{r}}{S_{\mathrm{usb}}}+j \omega_{\mathrm{usb}} L_{r}} \\
\mathbf{I}_{\mathrm{lsb} \_} r & =\mathbf{I}_{s_{-} \mathrm{lsb}} \frac{j \omega_{\mathrm{lsb}} L_{m}}{j \omega_{\mathrm{lsb}} L_{m}+\frac{R_{r}}{S_{\mathrm{lsb}}}+j \omega_{\mathrm{lsb}} L_{r}}
\end{aligned}
$$

\section{CAse Study}

\section{A. $7.5 \mathrm{~kW}$ induction motor simulation with constant load}

As an illustrative simulation example, a Toshiba $7.5 \mathrm{~kW}$, $50 \mathrm{~Hz}$ induction motor (the motor parameters are given in Appendix A) was chosen for analysis using both the dynamic model and per-phase equivalent method. According to Fig. 2, the dynamic model can be established by using MATLAB/Simulink. Furthermore, a three-phase power supply with a regular sinusoidal modulation frequency can be defined based on (2) and neglecting the source impedance. The induction motor stator and rotor current can be calculated by applying (12) and (14). The simulation results showing both stator and rotor current characteristics, including the dynamic model analysis and the per-phase equivalent calculation, are summarised in Fig. 5 - Fig. 8.

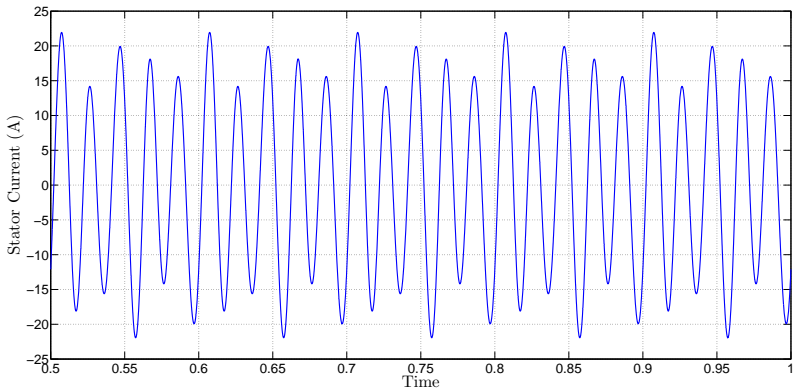

(a) Stator current waveform

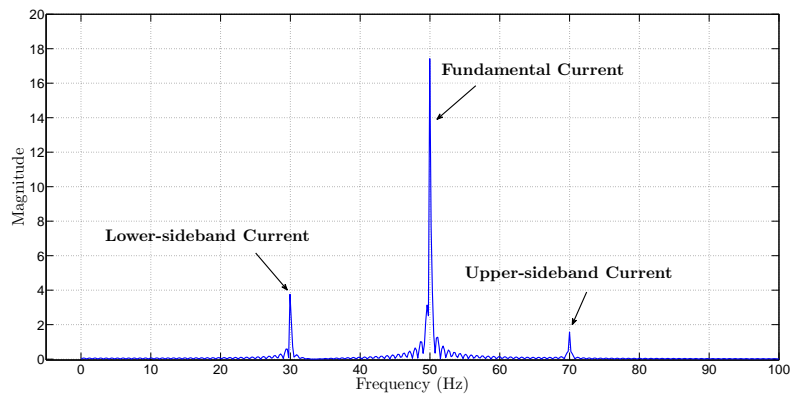

(b) Stator current frequency spectrum

Fig. 5. Stator current profile under $10 \%$ voltage change and $20 \mathrm{~Hz}$ modulation frequency condition

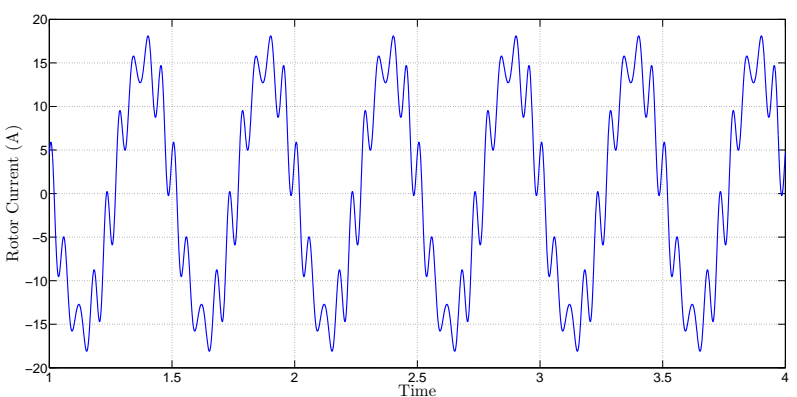

(a) Rotor current waveform

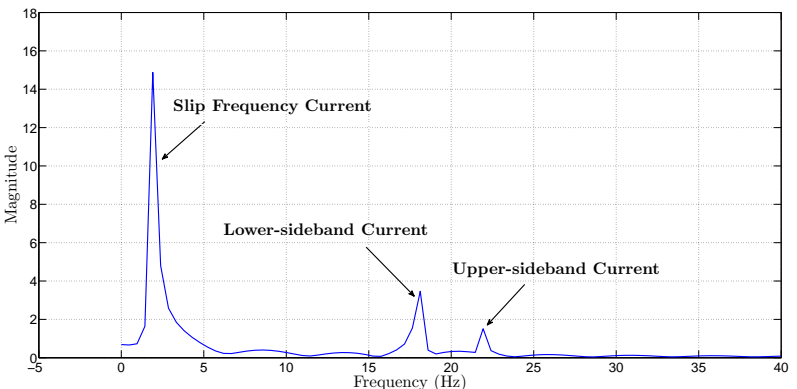

(b) Rotor current frequency spectrum

Fig. 6. Rotor current profile under $10 \%$ voltage change and $20 \mathrm{~Hz}$ modulation frequency condition 


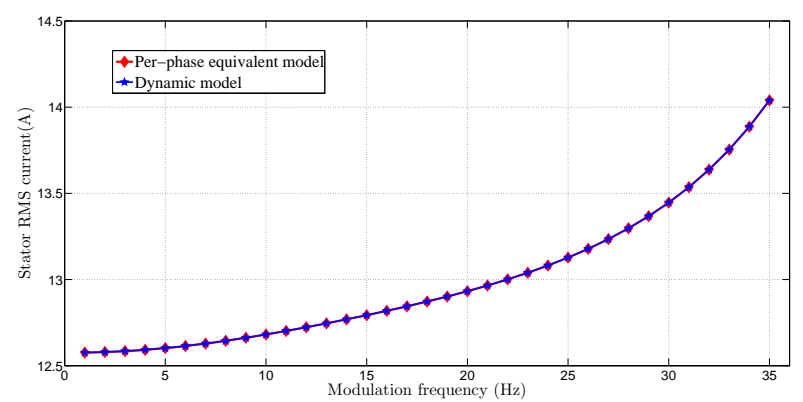

(a) Comparison of induction motor stator RMS current established by per-phase equivalent model and dynamical model respectively

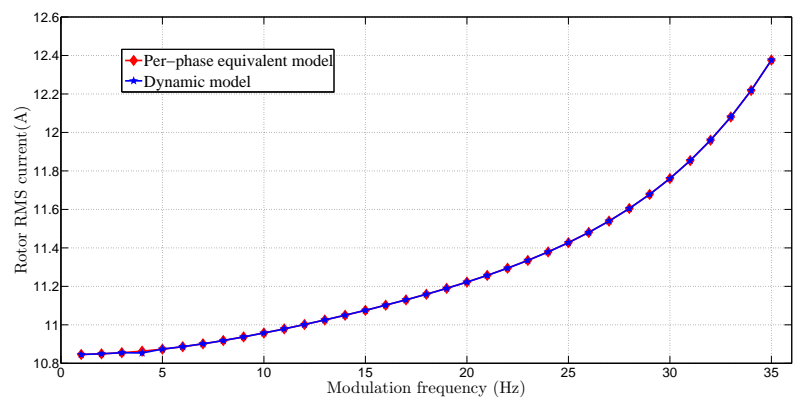

(b) Comparison of induction motor rotor RMS current established by perphase equivalent model and dynamical model respectively

Fig. 7. Comparison of per-phase equivalent model and dynamical mode respectively

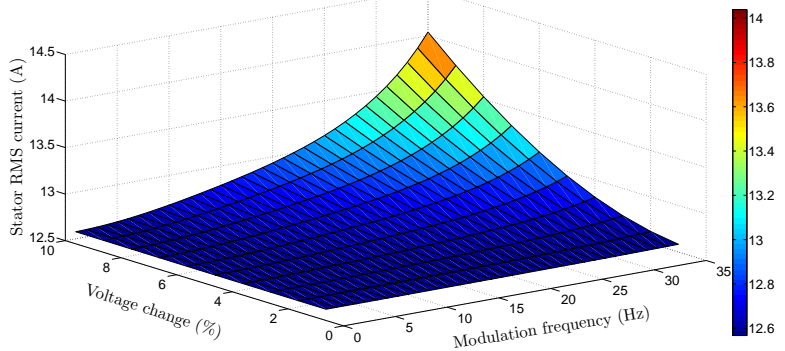

(a) Induction motor stator RMS current with various voltage fluctuation conditions

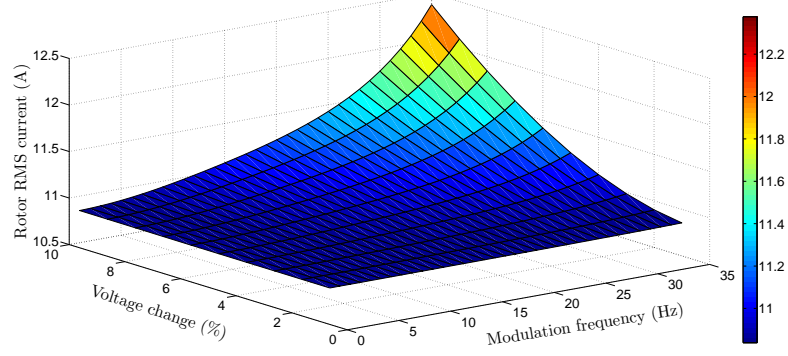

(b) Induction motor rotor RMS current with various voltage fluctuation conditions

Fig. 8. Stator and rotor RMS current simulation results
The induction motor stator and rotor current waveforms and corresponding frequency analyses are illustrated in Fig. 5 and Fig. 6 when it is subject to a $10 \%$ voltage magnitude change and $20 \mathrm{~Hz}$ modulation frequency. For the stator current, figures illustrate that the modulation frequency $(20 \mathrm{~Hz})$ component appears as an upper-sideband $\left(f_{c}+f_{m}\right)$ and lower-sideband $\left(f_{c}-f_{m}\right)$ in the stator current frequency spectrum, which is centred around the fundamental frequency. The modulation frequency voltage causes rotor current distortion as well. The reader should note that two frequency sidebands appear, which are centred around the modulation frequency and the relative upper-sideband and lower-sideband can be defined as $\left(f_{m}+f_{s}\right)$ and $\left(f_{m}-f_{s}\right)$. Furthermore, both Fig. 5 and Fig. 6 frequency analysis shows the lower-sideband current magnitude higher than the upper-sideband. The reason why the lower-sideband current magnitude is higher is that the induction motor reactance at the lower frequency is less than that at the higher frequency sideband higher. Mathematically, this can be explained by comparing $\mathbf{I}_{s_{-} u s b}, \mathbf{I}_{s_{-} \text {lsb }}$ and $\mathbf{I}_{r_{-} u s b}$, $\mathbf{I}_{r \text { lsb }}$ as defined in (12) (14).

The induction motor stator and rotor RMS currents which are calculated through the per-phase equivalent model and dynamical model respectively with a voltage change rate of $10 \%$ and various modulation frequencies $(1-35 \mathrm{~Hz})$ are illustrated in Fig. 7. The curves are well correlated. Therefore, the proposed per-phase equivalent method can be considered one convenient method to analyse the induction motor stator and rotor current when considering the mechanical load driven by the motor as constant.

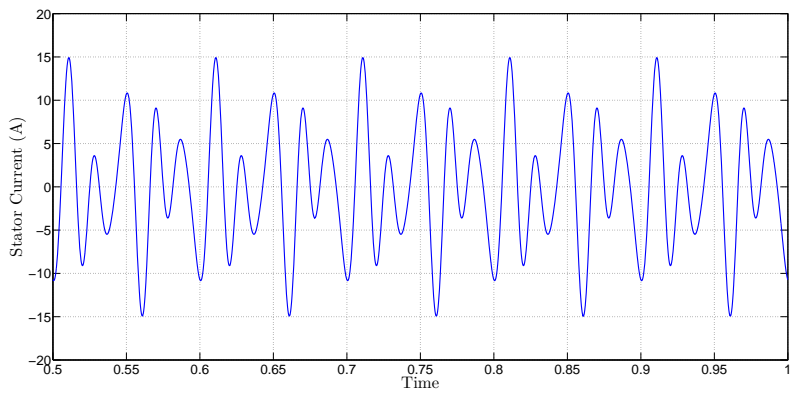

(a) Stator current waveform

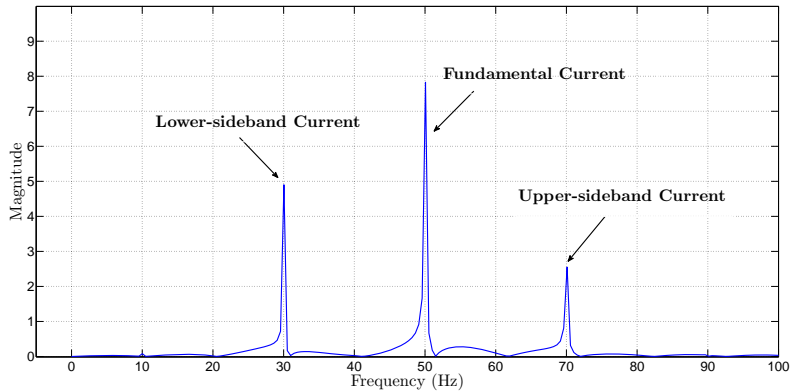

(b) Stator current frequency spectrum

Fig. 9. $7.5 \mathrm{~kW}$ induction motor stator current profile of simulation results when subject to $10 \%$ voltage change and $20 \mathrm{~Hz}$ modulation frequency condition

By investigating the stator and rotor current performance with voltage change magnitudes from $1 \%-10 \%$ and modulation frequencies from $1 \mathrm{~Hz}-35 \mathrm{~Hz}$, the stator RMS current trend can be summarised in Fig. 8(a) and rotor RMS current 


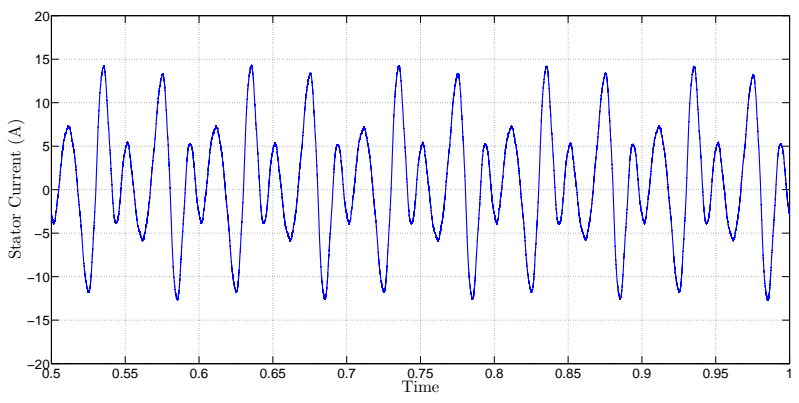

(a) Stator current waveform

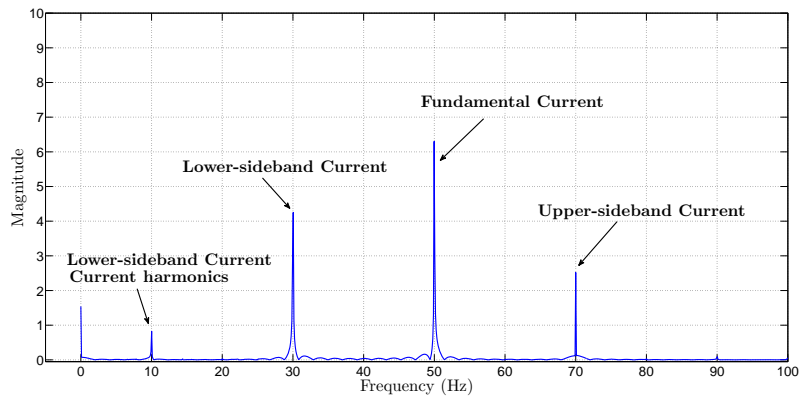

(b) Stator current frequency spectrum

Fig. 10. $7.5 \mathrm{~kW}$ induction motor stator current profile of experimental results when subject to $10 \%$ voltage change and $20 \mathrm{~Hz}$ modulation frequency

increase can be shown in Fig. 8(b). As can be seen, the stator and rotor RMS current curves show that the voltage $(\Delta V)$ and modulation frequency $\left(f_{m}\right)$ are the main reasons behind the RMS current increase. Fig. 8 also indicates that stator and rotor RMS current increases quickly under higher voltage change rates and higher modulation frequencies. The worst voltage fluctuation condition (10\% voltage change and $35 \mathrm{~Hz}$ modulation frequency) indicates that the stator and rotor RMS current increase about $11.7 \%$ and $14.2 \%$ respectively, compared to the no voltage fluctuation condition. This implies that the stator winding power loss will increase by $24.8 \%$ and the rotor losses by $30.4 \%$.

\section{B. $7.5 \mathrm{~kW}$ induction motor experiment work without load}

For experimental verification, a $7.5 \mathrm{~kW}, 50 \mathrm{~Hz}$ Toshiba induction motor without load was used. The power was supplied through a through a programmable power supply. The corresponding simulation analyses were established by using a load torque of zero. Figs $9-11$ summarise the relative simulation and experimental results.

The stator current and rotor current waveforms and corresponding frequency analyses are illustrated in Fig. 9 and Fig. 10 when subject to $10 \%$ voltage magnitude change and 20 $\mathrm{Hz}$ modulation frequency power supply. As can be seen, the stator current waveform of the simulation results is similar to the experimental results. Both waveforms display a serious distortion caused by the voltage fluctuations. The modulation frequency $(20 \mathrm{~Hz})$ component appears as an upper-sideband $\left(f_{c}+f_{m}\right)$ and as a lower-sideband $\left(f_{c}-f_{m}\right)$ in both the simulation and experimental frequency spectrums which can be seen in Fig. 9(b) and Fig. 10(b) respectively. However, a key difference between the simulation and experimental work, is that in Fig 10(b) (experimental stator current frequency

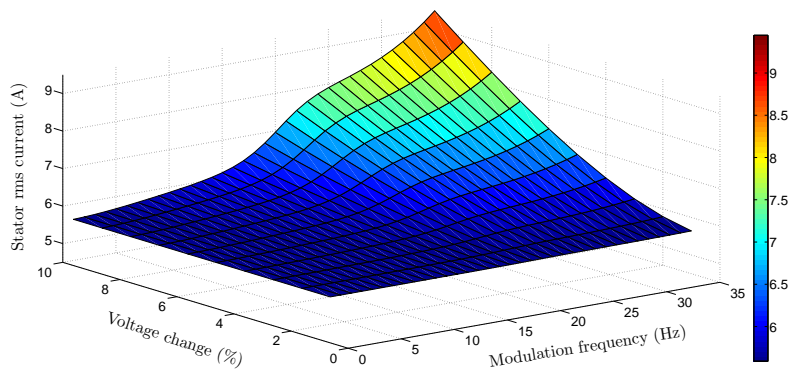

(a) Simulation results

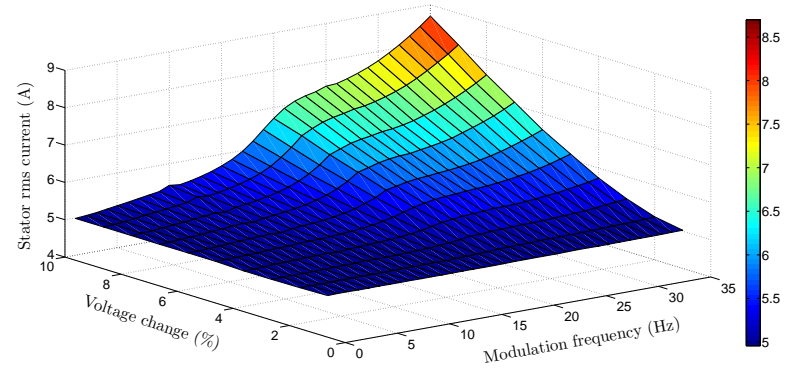

(b) Experimental results

Fig. 11. Induction motor stator RMS current with various voltage fluctuation conditions

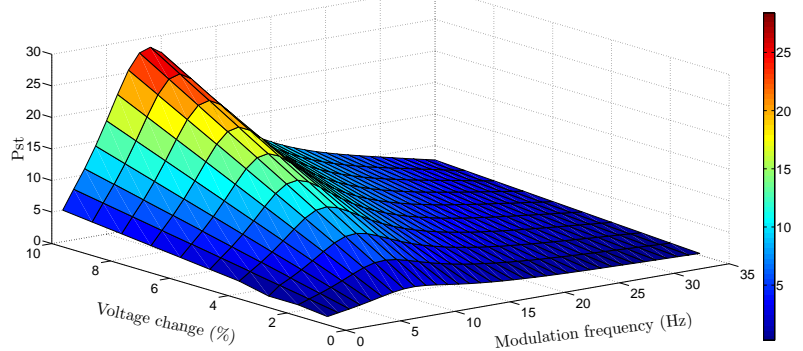

Fig. 12. $P_{s t}$ with different voltage change and modulation frequency

spectrum analysis), the lower-side band current harmonic displays at $10 \mathrm{~Hz}\left(f_{c}-2 f_{m}\right)$, however, the upper-side band current harmonic $\left(f_{c}+2 f_{m}\right)$ is too small to observe.

By investigating the stator current performance with voltage change from $1 \%-10 \%$ and modulation frequencies from 1 $\mathrm{Hz}-35 \mathrm{~Hz}$, the stator RMS current characteristics can be summarised in Fig 11. Comparing the two surface curves, the experimental results are in good agreement with the simulation work. Both results show that the stator RMS current will increase quickly under higher voltage change and higher modulation frequencies. The worst voltage fluctuation condition ( $10 \%$ voltage change and $35 \mathrm{~Hz}$ modulation frequency) indicates that the stator RMS current increases by about $69 \%$ in simulation and $74 \%$ in practice respectively. This means that the stator winding loss will increase $185.6 \%$ for simulation and $202.8 \%$ for experimental work when without load or little load condition. Obviously, this trend will lead to induction machine temperature increases and accelerate the machine ageing process.

However, this risky situation cannot be represented by using 
the flicker level index $P_{s t}$ since $P_{s t}$ is derived from the impact perceived by the human eye to light flicker. The $P_{s t}$ level is illustrated in Fig. 12 with various voltage change rates and modulation frequencies. According to the $P_{s t}$ curve, the peak value arises at approximately $8 \mathrm{~Hz}$ and decreases as the modulation frequency increases. Comparing Fig. 8, Fig. 11 and Fig. 12, there is a higher stator RMS current but lower flicker level under high voltage change and high modulation frequency conditions. Thus, $P_{s t}$ is not appropriate for determining power system electromagnetic compatibility levels and planning levels by only applying $P_{s t}$ values. In addition, relaxation of allowable flicker levels will raise the potential detrimental risk for induction motor ageing process.

\section{CONCLUSION}

An investigation has been carried out to examine the induction motor stator and rotor current characteristic when subjected to regular voltage fluctuations. The dynamical model and proposed per-phase equivalent model are applied to simulate an induction motor stator and rotor current variations assuming a constant load torque. Furthermore, the experimental work with comparative simulation work is reported for the case with no load torque. Both simulation and experimental results indicate that the induction motor stator and rotor RMS current increase considerably when subjected to high values of voltage change and modulation frequencies, with full-load and no-load. This trend can be observed clearly through respective three-dimensional surfaces. It is clear that the problems that the voltage fluctuation phenomenon will cause are not indicated by applying the traditional flicker index $P_{s t}$. Therefore, a new or advanced voltage fluctuation index needs to be proposed in order to indicate the elevated risk to electrical equipment.

\section{APPENDIX A \\ INDUCTION MOTOR PARAMETER}

$7.5 \mathrm{~kW}$ Three phase induction motor (Toshiba):

TABLE I

NAMEPLATE RATING:

\begin{tabular}{|c||c||c||c||c|}
\hline Type & Form & Volts & Full load (A) & $\mathrm{Hz}$ \\
\hline IK & FBKW & 415 & 14.4 & 50 \\
\hline \hline Poles & Speed Full Load & Insulation Class & Time Rating & Design \\
\hline 4 & 1440 & F & MCR & B \\
\hline
\end{tabular}

TABLE II

TEST CharaCteristics: BetweEn LINE $20^{\circ}$ C STATOR: $0.9447 \Omega$

\begin{tabular}{|c||c||c|}
\hline \multicolumn{3}{|c|}{ No load Test $50 \mathrm{~Hz}$} \\
\hline Volts & Amp. & Walts \\
\hline 415 & 5.82 & 400 \\
\hline \hline \multicolumn{2}{|c|}{ Locked Rotor Test $50 \mathrm{~Hz}$} \\
\hline Volts & Amp. & Walts \\
\hline 84 & 14.5 & 1060 \\
\hline \hline \multicolumn{3}{|c|}{ Locked Rotor Test $25 \mathrm{~Hz}$} \\
\hline Volts & Amp. & Walts \\
\hline 50.5 & 14.5 & 800 \\
\hline
\end{tabular}

\section{REFERENCES}

[1] R. Cai, J. Cobben, J. Myrzik, J. Blom, and W. Kling, "Flicker responses of different lamp types," Generation, Transmission Distribution, IET, vol. 3, no. 9, pp. 816-824, September 2009.

[2] C. Medeiros and J. de Oliveira, "Effects of voltage fluctuation associated to flicker limits on equipments performance," in 10th International Conf. Harmonics and Quality of Power, 2002., vol. 1, Oct. 2002, pp. 347-352 vol.1.

[3] J. Baptista, J. Gon andalves, S. Soares, A. Valente, R. Morais, J. BulasCruz, and M. Reis, "Induction motor response to periodical voltage fluctuations," in Electrical Machines (ICEM), 2010 XIX International Conference on, Sep. 2010, pp. 1-6.

[4] G. Bucci, E. Fiorucci, A. Ometto, and N. Rotondale, "The evaluation of the effects of the voltage amplitude modulations on induction motors," in Power Tech, 2005 IEEE Russia, June 2005, pp. 1-6.

[5] S. Tennakoon, S. Perera, and D. Robinson, "Flicker attenuation-part i: Response of three-phase induction motors to regular voltage fluctuations," Power Delivery, IEEE Trans. on, vol. 23, no. 2, pp. 1207-1214, April 2008.

[6] S. Duarte and N. Kagan, "A power-quality index to assess the impact of voltage harmonic distortions and unbalance to three-phase induction motors," Power Delivery, IEEE Trans. on, vol. 25, no. 3, pp. $1846-1854$, July 2010.

[7] Electromagnetic compatibility (EMC) - Limits - Assessment of emission limits for fluctuating loads in MV and HV power systems (IEC 610003-7:1996, MOD), AS/NZS 61000.3.7:2001 Std.

[8] C. Vilar Moreno, H. Amaris Duarte, and J. Usaola Garcia, "Propagation of flicker in electric power networks due to wind energy conversions systems," Energy Conversion, IEEE Trans. on, vol. 17, no. 2, pp. 267 -272 , Jun 2002

[9] M. Marei, E. El-Saadany, and M. Salama, "An intelligent control for the dg interface to mitigate voltage flicker," in Applied Power Electronics Conference and Exposition, 2003. APEC '03. Eighteenth Annual IEEE, vol. 1, Feb. 2003, pp. $179-183$ vol.1.

[10] Electromagnetic compatibility (EMC) - Testing and measurement techniques - Flickermeter - Function and design specifications, AS/NZS 61000.4.15:2005 Std.

K. Zhao (S'2010) is a Ph.D. candidate at the University of Wollongong, Australia. His research interests include power quality and the effect of power quality on equipment operation and lifetime.
S. Perera (M'1995) received the B.Sc.(Eng) degree in electrical power engineering from the University of Moratuwa, Sri Lanka, a M.Eng.Sc. degree from the University of New South Wales, Australia, and the Ph.D. degree from the University of Wollongong, Australia. He has been a lecturer at the University of Moratuwa, Sri Lanka. Currently he is an Associate Professor with the University of Wollongong. He is the Technical Director of the Endeavour Energy Power Quality and Reliability Centre at the University of Wollongong.

P. Ciufo (SM'2007) graduated from the University of Wollongong with a B.E. (Hons) in Electrical Engineering in 1990 whilst also completing an Industry Cadetship. He obtained an M.E. (Hons) in Electrical Engineering in 1993. He joined the academic staff of the University after completing his Ph.D. in 2002. Dr Ciufo has had various stints in industry as an Electrical Engineer and returned to academia in 2007. His research interests include Modelling and Analysis of Power Distribution Systems, Advanced Distribution Automation, Modelling and Analysis of AC Machines, Power System Harmonics and Power System Reliability. 